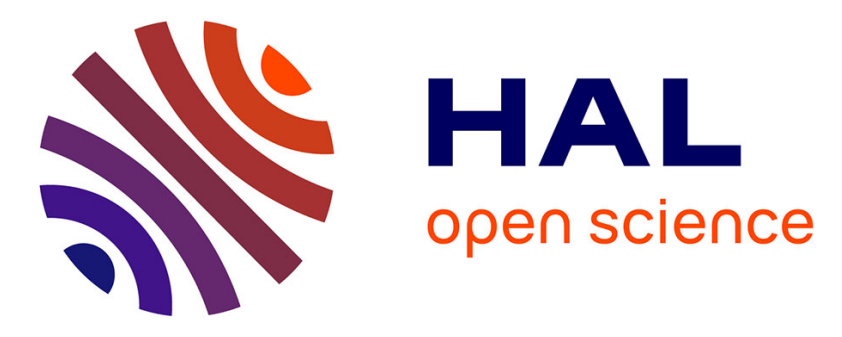

\title{
Beyond biofuels: economic opportunities, recent advances and challenges in property modeling for vegetable oils
}

Moises Teles dos Santos, Vincent Gerbaud, Galo Antonio Carrillo Le Roux

\section{- To cite this version:}

Moises Teles dos Santos, Vincent Gerbaud, Galo Antonio Carrillo Le Roux. Beyond biofuels: economic opportunities, recent advances and challenges in property modeling for vegetable oils. Green Processing and Synthesis, 2014, vol. 3 (n 6), pp. 401-410. 10.1515/gps-2014-0050 . hal-01123512

\section{HAL Id: hal-01123512 \\ https://hal.science/hal-01123512}

Submitted on 5 Mar 2015

HAL is a multi-disciplinary open access archive for the deposit and dissemination of scientific research documents, whether they are published or not. The documents may come from teaching and research institutions in France or abroad, or from public or private research centers.
L'archive ouverte pluridisciplinaire HAL, est destinée au dépôt et à la diffusion de documents scientifiques de niveau recherche, publiés ou non, émanant des établissements d'enseignement et de recherche français ou étrangers, des laboratoires publics ou privés. 


\section{Open Archive TOULOUSE Archive Ouverte (OATAO)}

OATAO is an open access repository that collects the work of Toulouse researchers and makes it freely available over the web where possible.

This is an author-deposited version published in : http://oatao.univ-toulouse.fr/ Eprints ID : 12223

\section{To link to this article :}

DOI : $10.1515 / g p s-2014-0050$

URL : http://dx.doi.org/10.1515/gps-2014-0050

\section{To cite this version :}

Teles dos Santos, Moises and Gerbaud, Vincent and Le Roux, Galo A.C. Beyond biofuels: economic opportunities, recent advances and challenges in property modeling for vegetable oils. (2014) Green Processing and Synthesis, vol. 3 ( $\mathrm{n}^{\circ}$ 6). pp. 401-410. ISSN 21919542

Any correspondance concerning this service should be sent to the repository administrator: staff-oatao@ listes-diff.inp-toulouse.fr 


\section{Beyond biofuels: economic opportunities, recent advances and challenges in property modeling for vegetable oils}

\begin{abstract}
Despite the greater attention given to biofuels application in the literature, there are many economic and environmental drivers to use vegetables oils (VOs) as a renewable feedstock for other applications. These drivers are discussed in the present work and the technological challenges imposed by this shift towards new VOs uses are also discussed. They are mainly associated to the reaction routes issues, the performance regarding enduser properties, experimental procedures and property prediction models. The need for more holistic approaches (life cycle analysis) is briefly discussed and the potential benefits arising from new computer-aided tools are highlighted as well.
\end{abstract}

Keywords: computer-aided design; fatty acids; modeling; triacylglycerols; vegetable oils.

DOI 10.1515/gps-2014-0050

\section{Introduction}

The social claims for "green products" and the environmental regulations have settled an agenda for industry and academic researchers to improve the use of waste and agricultural resources to develop new products. Among these resources, vegetable oils (VOs) are of great importance in terms of the technological issues and strategic

\footnotetext{
*Corresponding author: Moisés Teles dos Santos, LSCP/CESQ, Department of Chemical Engineering, University of São Paulo, Av. Prof. Luciano Gualberto 380, São Paulo 05508 900, Brazil, e-mail:moises.teles@usp.br

Vincent Gerbaud: Laboratoire de Génie Chimique (LGC), INP-ENSIACET, 4 Allée Emile Monso, Toulouse 31432, France Galo A.C. Le Roux: LSCP/CESQ, Department of Chemical Engineering, University of São Paulo, Av. Prof. Luciano Gualberto 380, São Paulo 05508 900, Brazil
}

policies about land usage, food security, biofuels production and others non-food applications. Experimental studies have evaluated the potential of VOs as a raw material in the synthesis of fine chemicals and polymers. New opportunities are also rising, as effort grows towards the use of agricultural resources in the synthesis of products classically derived from petrochemical molecules. The objective of this work is to briefly discuss the opportunities for the Green Process Engineering community in applying the emerging experimental and modeling tools to improve the use of VOs in the design of products with enhanced environmental and physical properties. The current scenario of world market, the opportunities arising from the biodiversity, the classical uses and emerging technologies, the technological challenges and the role of computational tools in product development are briefly discussed as well.

\section{Environmental and economic drivers}

VOs are less toxic, less polluting and harmless to the environment. They have advantageous environmental-healthsafety (EHS) properties, such as a good biodegradability, a low volatility and a high flash point. This is particularly important in applications where mineral oils show drawbacks in these properties (e.g., surface coatings). Their use for biofuels has attracted a considerable attention from the scientific community (experimental and modeling). The importance of bio-based fuels for energy policy is well-recognized. However, there is a majority of industrial uses other than biofuels needing improvements in processes, products and methods. Despite the sharp growth rate for biodiesel production in the last few years, there is a well established and large industry that uses VOs for other purposes. Among them, the use of edible oils for foods remains very important. The OECD-FAO [1] 
indicates that the share of VO consumption used for world biodiesel production is expected to increase from $12 \%$ in 2011-2013 to $14 \%$ in 2023. In other words, VO consumption for non-biofuel uses is expected to correspond to $86 \%$ of the world VO production in 2023 (Figure 1), with a high share of edible oils used as food. According to the Food and Agriculture Organization (FAO) of the United Nations, the major driving force on the demand side in recent years has been the non-food use of VOs (paints, detergents, lubricants, oleochemicals in general and biodiesel) with China and the European Union being major contributors to this growth [2]. Therefore, a well-settled and large demand for other fat-based products rather than biodiesel exists, with the particular technological and scientific challenges not yet fully addressed.

In developing countries, such as China and India, the rapid growth of VOs consumption for food has been responsible in a large extend for the increases achieved in their total food consumption (national averages $\mathrm{kcal} /$ person/day). VOs still have significant scope for consumption increases in most developing countries to achieve food security [2]. The biofuel demand also increases, although there are some projections that the boost to the oilseeds sector coming from biofuels may be weakening over time and could level off in the long term (2020) [2]. In summary, one has the following issues regarding the world VOs market:

- Demand pressure for food: population and economic growth in developing countries.

- Demand pressure for industrial uses: paints, detergents, lubricants, oleochemicals in general and biodiesel.
- Agricultural land expansion, water usage, ecological footprint of the whole chain of production.

- Concentration of production in a small number of crops and countries.

To better address these issues, technology (at all levels of product and process design) plays a central role. As discussed in the following section, exploring the diversity of feedstocks can open opportunities for the local economy development and to overcome the current concentration of production.

\section{Feestocks variability}

The VOs market is characterized by the concentration of production growth in a small number of crops and countries. Three oil crops (palm, soybeans and rapeseed) account for $69 \%$ of the world production and they provide $82 \%$ of the total increment in the world oil crop production since 1990. Also, a great part of the increases in these oil crops production comes from a small number of countries (Brazil, Argentina, United States, China, India, Malaysia, Indonesia, Canada and EU) [2].

However, there are much more feedstocks underexploited. In a recently developed computational database for the storage, search and retrieve of physico-chemical properties of VOs [3], more than one hundred feedstocks have been identified, but the total number of entries of oilseeds, vegetable fats and fruit-kernel oils can be over 300 . The biodiversity offers a great variability of feedstocks,

Projections of share of vegetable oil consumption: World (2023)

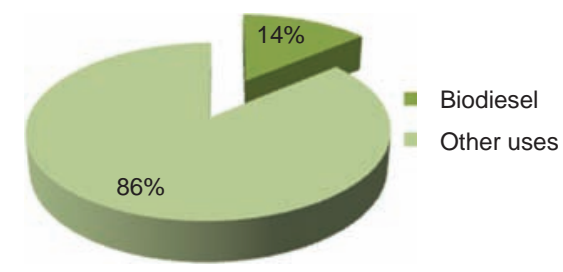

Projections of share of vegetable oil consumption: Brazil (2023)

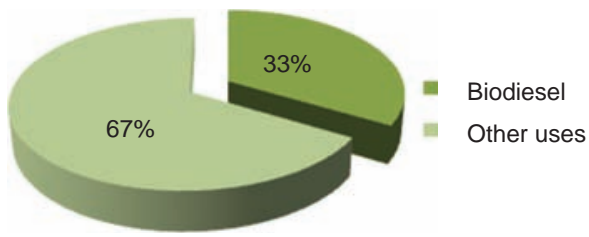

Projections of share of vegetable oil consumption: EU (2023)

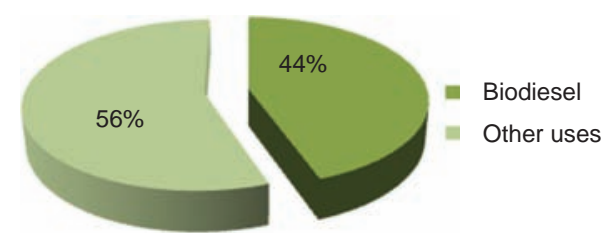

Figure 1 Share of vegetable oil consumption used for biodiesel production. Source: OECD-FAO [1]. 
with different physical properties and multiple possibilities of blends. Figure 2 shows a snapshot of the very first and final examples sorted in alphabetical order. To look for alternative and highly productive feedstocks to meet future demand for biofuels, chemicals and food seems, therefore, reasonable.

Despite the large variability in feedstocks, some issues must be taken into account concerning their advantages, limits and viability. Elbehri et al. [4] discuss that despite the advantages of biofuel investments for rural development, “... obstacles to biofuel growth remain in developing countries: lack of qualified labor, basic infrastructure and the investment capital needed to develop feedstock supply chains". Land acquisition for large scale biofuel projects and the potential conflict with traditional land rights, access and use are also issues to be aware of [4]. We believe that these issues also concern the use of VOs for other purposes other than biofuels. However, the opportunities to develop local economies by exploring potential oilseed crops and underexploited feedstocks remain. The biodiversity of oilseed plants in developing regions, such as northeast Brazil or the Amazonian region has attracted attention. Many studies are being undertaken to evaluate the production potential of oil plants and also to characterize their physical properties, oil yield and fatty acid profiles for food, energy or oleo chemicals requirements. Some examples are:

Northeast Brazil: Anemopaegma laeve, Pyrostegia venusta, Tabebuia impetiginosa, Oiticica (Licania rigida Benth), Buriti (Mauritia flexuosa L.), Macaúba (Acrocomia aculeata), Babaçu (Orbignya phalerata), Pequi (Caryocar brasiliense) and Tucumã (Astrocaryum aculeatum Meyer) $[5,6]$.
Amazonian region: Brazil nut (Bertholletia excelsa), andiroba (Carapa guianensis), cupuaçu (Theobroma grandflorum), murumuru (Astrocaryium murumuru), passion fruit (Passiflora spp.) and ucuba (Virola sebifera) are examples of the many Amazonian vegetal species. Their oils and fats have found applications as nutritional, pharmaceutical, cosmetic, painting, and additive products $[7,8]$.

The biodiversity can offer opportunities to overcome the gap between the food and biofuels needs and expected main plant oils harvests. The technological improvements in the oil yields per hectare also play a central role in the land expansion issue. According to FAO [2], land expansion continues to play an important role in the growth of crop production. The land-intensive nature of oil crops imposes an environmental debate about land expansion and its consequences in forest or other ecologically valuable areas. As there is no costless resource, the debate about growth of the VOs production and its environmental impact must be enriched by including these issues.

\section{Vegetable oils in industry: classical uses and emerging technologies}

VOs are used in foods, biofuels, soaps, lubricants, cutting-fluids, surfactants, printing inks, solvents, paints/ coatings, varnish, plasticizers, insulating fluid, and as a lipidic medium in which cosmetic and pharmacological fine chemicals are dispersed. Beyond these classical

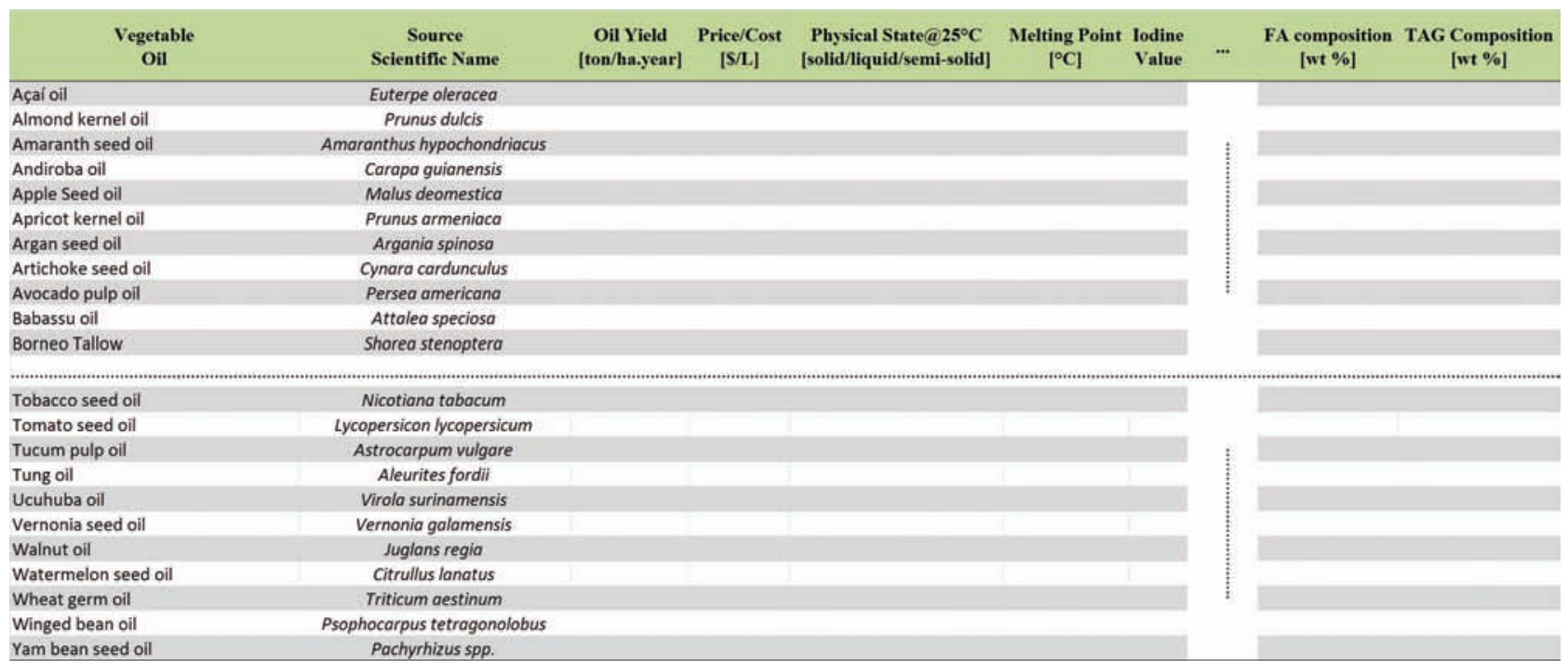

Figure 2 Reduced table of compiled feedstocks for oilseeds, vegetable fats and fruit-kernel oils. 
uses, new applications can be found through four main categories: 1) Direct use of VOs; 2) Modification of the triacylglycerols (TAGs) profile; 3) Use of glycerol as a platform for green chemicals and 4) Use of fatty acids as a platform for green chemicals. In the following sections, we briefly point out some aspects related to each one.

\subsection{Direct use of vegetable oils}

This can be of two types. The first one is to find new applications for known VOs. For example, soybean oil, the second most produced VO, is traditionally used in foods and personal care applications among others and has also a great potential to be used in lubricants [9]. Many VOs have also been applied as corrosion inhibitors and polymeric binders in coatings [10].

The second type consists in finding alternative VOs/ fats for a given application. The search for cocoa butter equivalents (CBE) is an example of this approach, in which the desired physical properties of cocoa butter are sought among other fats/oils mixtures [11].

Considering the large variety of feedstocks, it is reasonable to think that tailored blends could well provide alternatives solutions. However, the number of possible blends is extremely large and, as it will be discussed in the next sections, computational tools can be useful to cope with the large combinatorial problems for product design.

\subsection{Modification of the triacylglycerols profile}

VOs are mainly composed by TAGs. More than the fatty acid composition, it is the TAG composition (how the fatty acids are distributed in the glycerol structure) that controls the properties of VOs [12]. Figure 3 shows the typical molecular structure of fatty acids and TAGs. The demand for more sophisticated products increases and the simple physical mixture of VOs is not sufficient for matching the desired properties [13]. Other physical (fractionation) and chemical (hydrogenation, interesterification) processes can be used to change the TAG composition and then modify the physical properties of the initial raw materials.

In the food industry, the hydrogenation process has been associated with negative nutritional effects on consumers' health due to the formation of trans fatty acids. In this scenario, the chemical interesterification emerged as a useful technique to change physical properties of VOs blends for food development. This reaction uses catalysts (sodium methoxide, sodium metal) and heat to promote a random distribution of fatty acids among the three positions of the glycerol backbone (sn-1, sn-2 and sn-3, Figure 3). On the other hand, enzymatic interesterification uses regioselective lipases under mild reaction conditions to affect only specific positions of the glycerol backbone. Table 1 shows some different scales of study concerning vegetable oils and the corresponding research topics with some references. Not being exhaustive, this short list gives just a few examples for further reading.

Structured lipids are tailored TAGs, restructured by chemical or enzymatic reactions to change the stereochemical positions of fatty acids on the glycerol structure. The aim is to improve the nutritional or therapeutic properties for functional foods, while keeping the physical characteristics within the desired range [33]. Mediumlong-medium (MLM) and conjugated linoleic acids (CLA) TAGs are recognized for their improved nutritional characteristics. MLM has medium chain fatty acids (MCFA) (C6-C12) in stereo positions sn- 1 and sn-3 of the glycerol

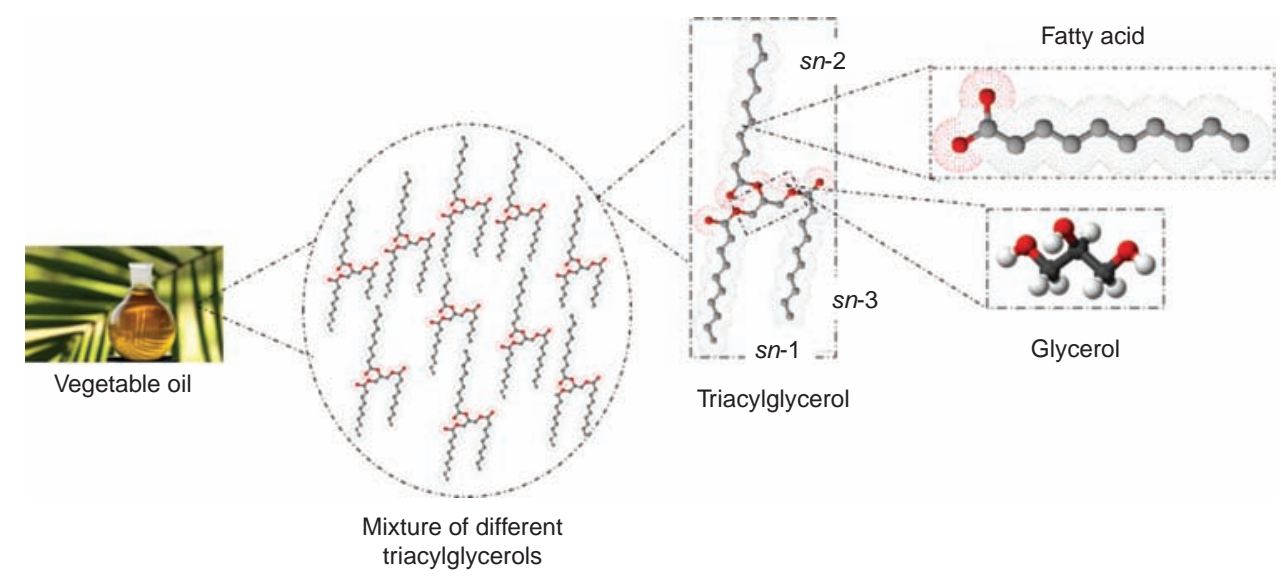

Figure 3 Molecular representation of vegetable oils chemical species (triacylglycerols, fatty acids and glycerol). 
Table 1 Research areas and corresponding references examples in each level of representation of Figure 3.

\begin{tabular}{llll}
\hline & Vegetable oils & $\begin{array}{l}\text { Modification of the } \\
\text { triacylglycerols profile }\end{array}$ & Fatty acids/glycerol \\
\hline Scope & Uses, main crops, composition, & Interesterification (experimental & Platform \\
& physical properties, refining & and modeling), change in & chemicals, nutritional \\
& process, analysis. & physical properties, blends. & aspects, structured lipids. \\
References & {$[14-17]$} & {$[12,13,18-25]$} & {$[26-35]$} \\
\hline
\end{tabular}

backbone and functional long-chain polyunsaturated fatty acids (PUFA) in position sn-2. The CLA is a general term for the positional and geometric isomers of the octadecadienoic acid with conjugated double bonds at carbon atoms $9 / 11$ or $10 / 12$ [36].

\subsection{Use of glycerol as a platform for green chemicals}

Glycerol (a by-product in the production of some biofuels) can be a platform chemical for a great variety of specialty chemicals. One example is the synthesis of propanediol, epichlorohydrin and acrylic acid. These compounds, classically synthesized by petrochemical based routes (using propene), are used, respectively, for the production of polymers, epoxy resins and various plastics, coatings, adhesives and elastomers. These chemicals can also be synthesized using glycerol as the starting material [26, 27]. Currently, propanediol can be synthesized from glycerol in one reaction step, whereas the petrochemical one uses two reaction steps. The glycerol-based route also avoids the carcinogenic intermediate propylene oxide [26]. Glycerol carbonate has also a large potential as a novel component of gas-separation membranes, solvent and biolubricant $[28,29]$

\subsection{Use of fatty acids as a platform for green chemicals}

The fatty acids present in VOs can be also used as starting materials for the synthesis of value-added chemicals. Double bonds present in some fatty acids represent suitable reactive sites. Fatty acids are a rich source of monomers that can be chemically functionalized to make biosourced polymers, such as diacids, polyacids, diols, polyols, diamines, polyamines, hydroxy acids, amino acids, polyaldehydes, vinyl compounds and polyurethanes [30]. Indeed, polyurethanes are one of the most promising area of interest of functionalized VOs/fatty acids and there are different synthesis routes for polyols at research or commercial stage, such as transesterification, hydroformylation, ozonolysis and thiol-ene coupling [30, 31]. There is a great variety of fatty acids (and consequently, a great variety of possible monomers) and this opens opportunities to polymers having new and enhanced properties. Besides polymers, coating for wood surfaces, PVC plasticizers, lubricants, surfactants and personal care products are also examples of products where fatty acids can be used.

\section{Technological challenges}

\subsection{Synthesis routes and performance of new chemicals}

Apart from the eco-friendly sound of bio-based chemicals, important issues related to synthesis and performance must also be considered. Regarding synthesis of VO- based products, toxic and hazardous co-reactants are still needed in some cases (e.g., isocyanate in the production of polyurethanes from VOs [31]). The use of hazardous solvents, the energy consumption, the cost and the by-products generation must be considered as well. In this context, the use of catalysts (enzymes) offers a potentially cleaner and more energy-efficient production than conventional chemical processes in oleochemistry [32]. The enzymatic route can lead to fewer by-products, simpler product recovery, less waste generation and higher yields. However, further developments in suitable enzymes that are not commercially available are necessary. This can involve genetic modifications on the organism that produces the enzyme to improve enzyme activity and stability under the process conditions [32].

The performance of the new chemicals at usage conditions is another important issue. Although VOs have advantageous properties (e.g., biodegradability, low volatility, high flash point), there are also drawbacks that must be overcome. The main issues limiting the use of 
VOs as industrial fluids are their low thermal and oxidation stability and poor low-temperature properties (as fatty acids and TAGs crystallize easily). Current studies aim to improve oxidation and low temperature stability; however, a generalized approach improving the overall performance of VOs as industrial fluids is still lacking [37]. In this context, the use of additives and the modification of the chemical structure of VO are an alternative. As an example, ethylene-vinyl acetate copolymer and ethyl cellulose have been tested to improve the thermal stability and to increase the viscosity range of different VOs [38].

\subsection{Experimental measurements}

The availability of experimental data is critical for process and/or product modeling, simulation and design. If the computational tools traditionally used in the chemical/ petrochemical industry is to be used in the oil and oleochemical industry, the physico-chemical properties of lipid compounds present in VOs must be known.

Natural VOs can be formed by dozens of different chemical species, such as acylglycerols (mono, di and triacylglycerols), free fatty acids, tocopherols, sterols, carotenes and minor compounds. The accurate separation, purification and identification of all lipid compounds are a difficult task. Bulk physical properties can be measured (e.g., viscosity, density, solid fat content) but the measured data of the pure components are still scarce when compared to other chemicals. If we consider just the TAGs part of the mixtures, uncertainties arise even from HPLC analysis. According to Lida et al. [18], many TAGs cannot be identified due to the lack of standards and the fact that TAGs with equivalent carbon numbers are very similar, thereby making their identification (based on relative retention times), difficult and uncertain. The lack of data is even more pronounced for temperature dependent properties (e.g., viscosity, vapor pressure, density, heat capacity and superficial tension). In such cases, it is difficult to obtain pure component data in a large range of temperatures.

Recent efforts have been made in order to compile and classify the chemical structures, physical and biological properties of different classes of lipids in a computational database. Examples are the LIPID BANK [39], the LIPIDAT [40, 41], the LIPID MAPS Structure Database (LMSD) [42] and the CAPEC Lipids Database [43]. Experiments are costly and time-consuming but experimental data form the basis of prediction models and parameter regressions.

\subsection{Property models}

Traditional group contribution (GC) methods, connectivity index and UNIFAC methods have been recently adapted to cover lipid systems [44-48]. These improvements rely on the revision of GCs parameters using a lipid database containing different classes of lipids (fatty acids, fatty esters, acylglycerols) and their experimental thermophysical properties. Therefore, they are strongly related to the previous experimental challenge, in particular for TAGs. As commented by Prausnitz et al. [49], we cannot get something from nothing, and predictive methods will continue to be dependent on reliable experimental data.

These new predictive models have the advantage that their parameters have been regressed using only lipids properties and they are expected to perform better than former general GC methods. Figure 4 shows a general

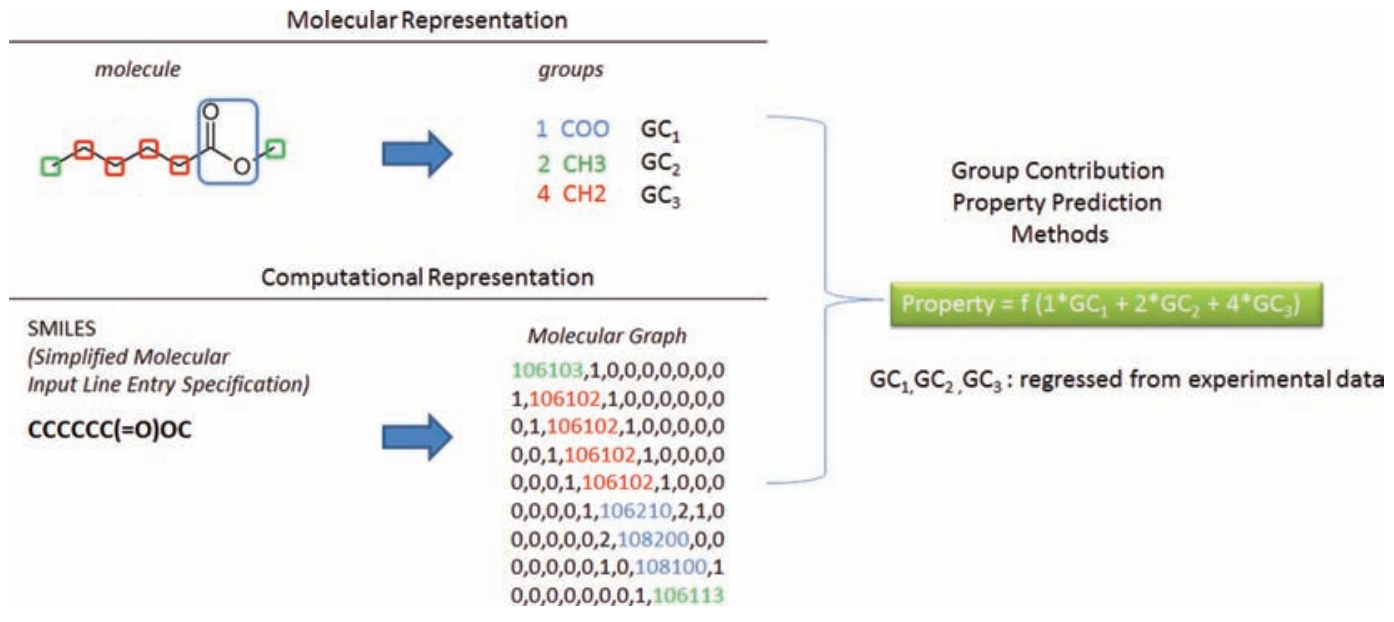

Figure 4 Molecular representation and computational representation of group contribution models for property predictions. 
methodology for depicting a molecule into functional groups, allowing to develop and use GC models.

This computational representation was implemented by some of the authors [50] to deal with bio-solvent design. In this approach, the SMILES notation of a molecule is automatically converted into a matrix (molecular graph) in which the atoms and bonds are identified.

Though the origins of current GC methods are over 50 years, lipid-based models have only recently been developed, as mentioned above. These improvements on thermophysical properties and mixture models have so far been mainly focused on improving the design of biorefinery processes through computational simulations. However, they are also useful for the design of products using VOs. Flöter [51] highlighted the importance of the melting point, the heat of fusion and of the solubility for food product development using fats. Crystallization (polymorphisms in solid state, kinetics of polymorphic transitions) and the resulting crystal habit and size are also of great importance for product development. In this context, modeling can help to design better experiments during the search for product solutions [51].

For product design, mixture models must include equilibrium models, in particular solid-liquid equilibrium (SLE), since many end-user properties (texture, creaminess, plasticity) depend on the careful control of the solid fat content (SFC).

In VOs, many properties are determined not only by the molecular structure but also by the crystalline arrangement between molecules, since TAGs can solidify in different crystals packing (polymorphism). The problem of SLE modeling has been addressed using different chemical species normally found in VOs (Figure 5). Even non-equilibrium (time-dependent) properties play an important role in products using VOs. This is the case of the kinetic of crystallization which influences the crystals shape and size that ultimately set the sensorial performance of fatty food products.
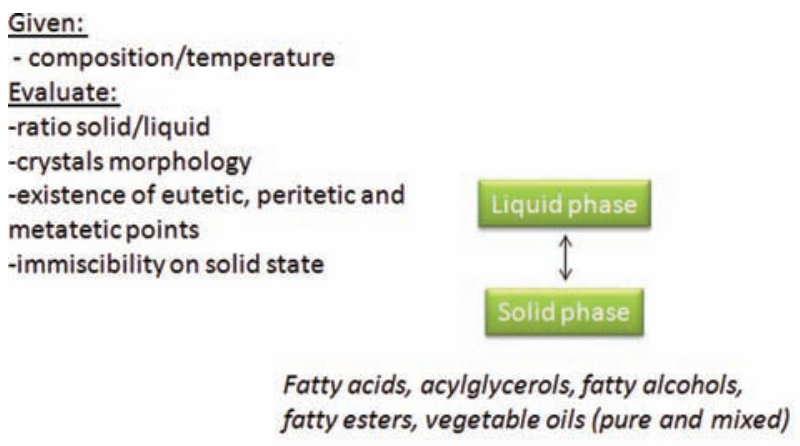

The polymorphism (crystals morphology) in the solid state (not covered by conventional GC methods) must be considered when designing tailored fat-based foods. The so-called topological indices can offer opportunities to improve description at this level, as they are able to predict properties with higher accuracy than simple GC techniques, taking into account three-dimensional steric effects [52]. Some powerful molecular dynamics models can also be found in literature [53], but these models remain time consuming and not suitable for large multicomponent problems.

Thermodynamic models can be found for pure, binary and ternary mixtures [54-56] and for multi-component mixtures $[12,57,58]$. The solid-liquid diagrams of various fatty mixtures are still unknown or were published with limited information, although such phase diagrams are a powerful tool for product development [59,60]. More empirical or semi-empirical methods, such neural networks [61] and different correlations, have also been used [62-64] aiming to predict the solid-liquid behavior in such mixtures. A broader and deeper review of the SLE problem can be found in Maximo et al. [60].

\subsection{Life cycle analysis for new chemicals and raw materials}

The life cycle analysis (LCA) has already been applied to biofuels production [65] and to the VO production step [66]. This holistic approach should be also extended for evaluating alternative uses of VOs. The goal is a broader knowledge of their impact on the environment and health. LCA must be used in the VOs crop as well as in the industrial production of the emerging chemicals derived from them. Indeed, when the whole chain of the processes involved is considered, unexpected conclusions can emerge. Törnvall and Hatti-Kaul [32]studied a comparative LCA of various wood coating products; they concluded

Pure, binary and ternary mixtures

-Thermodynamicmodels

-Phase diagramas

-Correlations

Multicomponent mixtures

-Thermodynamic models

-Neural networks

-Correlations

Figure 5 The solid-liquid equilibrium problem in some lipids and examples of strategies to cope with it. 
that a fossil feedstock-based coating was the most favorable with respect to many environmental categories (global warming, acidification, eutrophication and photochemical ozone). The lower environmental performance of the wax esters coatings based on VOs was mostly due to the negative effects of the rapeseed oil cultivation stage. This example demonstrates that a holist approach (like LCA) is necessary to measure the real impacts when comparing renewable and fossil feedstocks. The agricultural phase also imposes environmental constraints that must be considered (use of fertilizers, pesticides, steel for machines, land use, among others). As different VOs have different agricultural characteristics, it is important to consider that various crops can lead to diverse environmental performances. The diversity of raw materials and the multiple ways to combine them is a driver to computer-aided tools, as discussed in the following section.

\section{Computer-aided approach for product design}

Product development consists in finding the mixtures ingredients and their ratios. It is usually time and economically consuming. Statistical and mathematical techniques improve experiments, allowing a better understanding of how variables affect a target response and the interaction among them (e.g., Response Surface Methodology, Principal Component Analysis, D-optimal, G-optimal). In a scenario of opened market opportunities, the need for faster and costless procedures favors the use of computer-aided tools, promoting as a side effect the generation, storage, search and retrieve of relevant data for process and product design model development.

Computer-aided molecular design (CAMD) has emerged as a promising method of generating or searching in a database for molecules and/or mixtures satisfying a desired set of properties defined $a$ priori. This approach relies strongly in the availability and quality of property prediction methods. Property methods are not a novelty, but only recently predictive models for lipidbased systems have emerged (as discussed earlier). The CAMD method (used in solvents, polymers, refrigerants and pharmaceuticals design) must be extended to the design of value-added products derived from VOs, taking advantage of the recent progress in property prediction methods. As the number and quality of experimental data increase, one should shift from statistical approaches to more phenomenological models. As property methods are improved, more CAMD works (like that of Camarda and Sunderesan [52] and Heintz et al. [50]) can be performed.

Thus, the technological pathway for improving the use of computational tools in the VOs industry should include the three main integrated and dependent steps illustrated in Figure 6, each one having their own benefits, limitations and challenges.

The use of models and computational tools can lead to a scenario with a "dynamic data evaluation" as discussed by Frenkel [67]. In this approach, chemical process and product design is improved by a data-expert system software able to search, retrieve and fill data gaps on property data.

Each VO has its own fatty acid and TAG profile. The changes in composition mean changes in physical properties, leading to a large combinatorial number of possibilities when choosing the right formulation for a given application. Computational tools can be useful to handle the biodiversity of VOs and to cope with this combinatorial problem.

\section{Concluding remarks}

Improving the use of VOs is a multidisciplinary task, involving biology, chemistry, computer sciences,
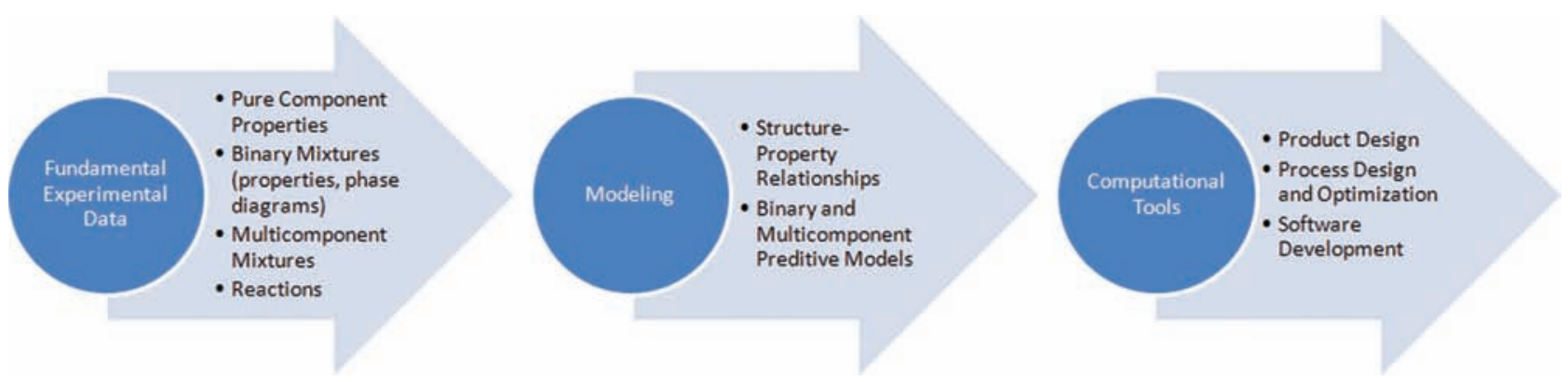

Figure 6 Technological pathways for improving computer-aided tools for the vegetable oils industry. 
thermodynamics and economy expertise. The large biodiversity, the green agenda, the emerging experimental works and modeling tools should be integrated with the help of computational approaches. This implies the use of tools not available when the traditional petrochemical industry was first developed, such as web-based, storage and communication tools that can improve the whole cycle of process and product development using VOs as sources of greener solutions.

Acknowledgments: We acknowledge the financial support received from CAPES (Coordenação de Aperfeiçoamento de Pessoal de Nivel Superior, Brazil), project CSF 057/2012. The authors wish to thank the anonymous reviewers for the helpful comments on the manuscript.

\section{References}

[1] OECD-FAO Agricultural Outlook 2014-2023, 2014.

[2] Alexandratos, N. and J. Bruinsma. 2012. World agriculture towards 2030/2050: the 2012 revision. ESA Working paper No. 12-03. Rome, FAO.

[3] Oliveira CC, Teles dos Santos M, Le Roux GA. In Anais do XX Congresso Brasileiro de Engenharia Química, 2014.

[4] Elbehri A, Segerstedt A, Liu P. Biofuels and The Sustainability Challenge: A Global Assessment of Sustainability Issues, Trends and Policies for Biofuels and Related Feedstocks, Rome, 2013.

[5] Pinho RS, Oliveira AFM, Silva SI. Bioresour. Technol. 2009, 100, 6114-6117.

[6] Bergmann J, Tupinambá D, Costa OY, Almeida JR, Barreto C, Quirino B. Renew. Sustain. Energy Rev. 2013, 21, 411-420.

[7] Bataglion GA, da Silva FMA, Santos JM, dos Santos FN, Barcia MT, de Lourenço CC, Salvador MJ, Godoy HT, Eberlin MN, Koolen HHF. Food Res. Int. 2014, 64, 472-481.

[8] Pardauil JJR, Souza LKC, Molfetta FA, Zamian JR, Rocha Filho GN, da Costa CEF. Bioresour. Technol. 2001, 102, 5873-5877.

[9] Adhvaryu A, Erhan SZ. Ind. Crops Prod. 2002, 15, 247-254.

[10] Alam M, Akram D, Sharmin E, Zafar F, Ahmad S. Arab. J. Chem. 2014, 7, 469-479.

[11] Lipp M, Anklam E. Food Chem. 1998, 62, 73-97.

[12] Teles dos Santos M, Gerbaud V, Le Roux GAC. Chem. Eng. Sci. 2013, 87, 14-22.

[13] Mat Dian NLH, Sundram K, Idris NA. J. Am. Oil Chem. Soc. 2006, 83, 739-745.

[14] Erhan SZ, Ed., Industrial Uses of Vegetable Oils. AOCS Press, Champaign, Illinois, 2005.

[15] Gunstone F, Ed., Vegetable Oils In Food Technology: Composition, Properties and Uses. CRC Press, UK, 2002.

[16] Shahidi F. Bailey's Industrial Oil and Fat Products, 6th ed., New York: Wiley, 2005.

[17] Harwood J, Gunstone F, Dijkstra AJ, Eds., The Lipid Handbook, 3rd ed. Florida: CRC Press, 2007.

[18] Lida HMDN, Sundram K, Siew WL, Aminah A, Mamot S. J Oil Fat Ind. 2002, 79, 1137-1144.
[19] Teles dos Santos M, Gerbaud V, Le Roux CAC. J. Food Eng. 2014, 126, 198-205.

[20] Rodrigues JN, Gioielli LA, Sim IS. J. Food Eng.2003, 57, 347-355.

[21] Rodrigues JN, Gioielli LA. Food Res. Int. 2003, 36, 149-159.

[22] Microstructure I, Rousseau D, Hill AR, Marangoni AG. J. Am. Oil Chem. Soc. 1996, 73, 973-981.

[23] Marangoni AG, Rousseau D. Food Res. Int. 1999, 31, 595-599.

[24] Petrauskaite V, De Greyt W, Kellens M, Huyghebaert A. J. Am. Oil Chem. Soc. 1998, 75.

[25] Ribeiro APB, Basso RC, Grimaldi R, Gioielli LA, Gonçalves LAG. Food Anal. Methods 2009, 2, 282-302.

[26] Metzger JO. Eur. J. Lipid Sci. Technol. 2009, 111, 865-876.

[27] Behr A, Eilting J, Irawadi K, Leschinski J, Lindner F. Green Chem. 2008, 10, 13.

[28] Pagliaro M, Ciriminna R, Kimura H, Rossi M, Della Pina C. Angew. Chem. Int. Ed. Engl. 2007, 46, 4434-4440.

[29] Vieville C, Yoo JW, Pelet S, Mouloungui Z. Catal. Lett. 1998, 60, 245-247.

[30] Petrovic Z. Polym. Rev. 2008, 48, 109-155.

[31] Nohra B, Candy L, Blanco J-F, Guerin C, Raoul Y, Mouloungui Z Macromolecules 2013, 46, 3771-3792.

[32] Törnvall U, Hatti-Kaul R. Lipid Technol. 2007, 9, 84-87.

[33] Osborn HT, Akoh CC. Comp. Rev. Food Sci. Food Safety 2002, 3 , 110-120.

[34] Alonso DL, Maroto FG. Biotechnol. Adv. 2000, 18, 481-497.

[35] Behr A, Gomes JP. Eur. J. Lipid Sci. Technol. 2010, 112, 31-50.

[36] Timm-Heinrich M, Skall Nielsen N, Xu X, Jacobsen C. Innov. Food Sci. Emerg. Technol. 2004, 5, 249-261.

[37] Adhvaryu A, Erhan S, Perez J. Wear 2004, 257, 359-367.

[38] Quinchia LA, Delgado MA, Reddyhoff T, Gallegos C, Spikes HA. Tribol. Int. 2014, 69, 110-117.

[39] Watanabe K, Yasugi E, Oshima M. Trends Glycosci. Glycotechnol. 2000, 12, 175-184.

[40] Caffrey M, Moynihan D, Hogan J. J. Chem. Inf. Model. 1991, 31 275-284.

[41] Caffrey M. Hogan J. Chem. Phys. Lipids 1992, 61, 1-109.

[42] Sud M, Fahy E, Cotter D, Brown A, Dennis EA, Glass CK, Merrill AH, Murphy RC, Raetz CRH, Russell DW, Subramaniam S. Nucleic Acids Res. 2007, 35, D527-D532.

[43] Díaz-Tovar C-A, Gani R, Sarup B. Fluid Phase Equilib. 2011, 302, 284-293.

[44] Ceriani R, Gani R, Meirelles AJA. Fluid Phase Equilib. 2009, 283, 49-55.

[45] Zong L, Ramanathan S, Chen C-C. Ind. Eng. Chem. Res. 2010, 49, 876-886.

[46] Cunico LP, Hukkerikar AS, Ceriani R, Sarup B, Gani R. Fluid Phase Equilib. 2013, 357, 2-18.

[47] Cunico LP, Ceriani R, Sarup B, O'Connell JP, Gani R. Fluid Phase Equilib. 2013, 362, 318-327.

[48] Hirata GF, Abreu CRA, Bessa LCBA, Ferreira MC, Batista EAC, Meirelles AJA. Fluid Phase Equilib. 2013, 360, 379-391.

[49] Poling BE, Prausnitz JM, O'Connell JP, Eds., The Properties of Gases and Liquids, 5th ed., McGraw-Hill, New York, 2001.

[50] Heintz J, Belaud J-P, Pandya N, Teles Dos Santos M, Gerbaud V. Comput. Chem. Eng. 2014, 71, 362-376.

[51] Flöter E. Eur. J. Lipid Sci. Technol. 2009, 111, 219-226.

[52] Camarda KV, Sunderesan P. Ind. Eng. Chem. Res. 2005, 44, 4361-4367. 
[53] Pink DA, Hanna CB, Sandt C, MacDonald AJ, MacEachern R, Corkery R, Rousseau D. J. Chem. Phys. 2010, 132, 054502.

[54] Rocha SA, Guirardello R. Fluid Phase Equilib. 2009, 281, 12-21.

[55] Maximo GJ, Carareto NDD, Costa MC, dos Santos AO, Cardoso LP, Krähenbühl MA, Meirelles AJA. Fluid Phase Equilib. 2014, 366, 88-98.

[56] Robustillo MD, Barbosa DF, Meirelles AJDA, Filho PDAP. Fluid Phase Equilib. 2013, 339, 58-66.

[57] Wesdorp L, Phase Equilibria in Fats. Theory and Experiments. Delft University of Technology, 1990.

[58] Won KW, Daniel F. Fluid Phase Equilib. 1993, 82, 261-273.

[59] Carareto NDD, Costa MC, Rolemberg MP, Krähenbühl MA, Meirelles AJA. Fluid Phase Equilib. 2011, 303, 191.e1-191.e8.

[60] Maximo GJ, Costa MC, Coutinho JAP, Meirelles AJA. RSC Adv. 2014, 4, 31840.

[61] Block JM, Barrera-Arellano D, Figueiredo MF, Gomide FAC. J. Am. Oil Chem. Soc. 1997, 74, 1537-1541.

[62] Braipson-Danthine S, Deroanne C. J. Am. Oil Chem. Soc. 2006, 83, 571-581.

[63] Augusto PED, Soares BMC, Chiu MC, Gonçalves LAG. Food Res. Int. 2012, 45, 132-135.

[64] Andreia Schäfer De Martini Soares F, Claro da Silva R, Caroline Guimarães da Silva K, Bertolessi Lourenço M, Ferreira Soares D, Antonio Gioielli L. Food Res. Int. 2009, 42, 1287-1294.

[65] Kralisch D, Staffel C, Ott D, Bensaid S, Saracco G, Bellantoni P, Loeb P. Green Chem. 2013, 15, 463.

[66] Spinelli D, Jez S, Basosi R. Process Biochem. 2012, 47, 1595-1602.

[67] Frenkel M. Comput. Chem. Eng. 2011, 35, 393-402.

\section{Bionotes}

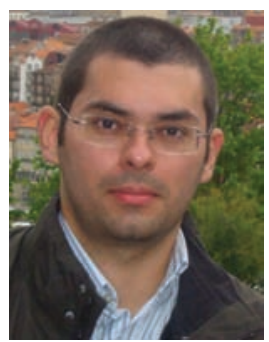

\section{Moisés Teles dos Santos}

Moisés Teles dos Santos is a postdoctoral fellow in the Chemical Engineering Department of the University of São Paulo (Brazil). He obtained his PhD in Process Engineering at the Institut National Polytechnique de Toulouse (France) and at the University of São
Paulo. His current research interest includes the development of models and computational tools for product design using biomass, covering bio-solvents and vegetable oil-based products. On the process level, his main interest is in the sustainability analysis of industrial systems using entropy analysis.

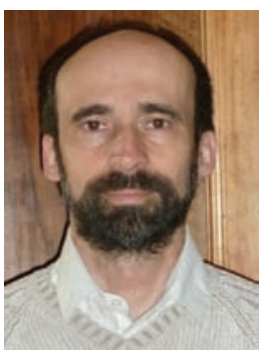

Vincent Gerbaud

Vincent Gerbaud is a research director at the French National Scientific Research Center CNRS at the Laboratoire de Génie Chimique in Toulouse. His field of research concerns modeling and simulation in process system engineering, with a strong interest in small scale modeling: molecular simulation, thermodynamics, computer-aided molecular and mixture design. At the process scale, he also focuses on the design and synthesis of distillation processes, for example, extractive and azeotropic distillation.

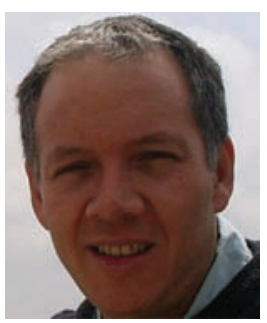

Galo A.C. Le Roux

Galo A.C. Le Roux obtained his PhD in Process Engineering at the Institut National Polytechnique de Toulouse in 1995. He is a full Professor at the Polytechnic School of the University of São Paulo (Brazil). He works in process modeling, simulation, synthesis and control with emphasis on parameter estimation and system identification (inverse problems). The domains of application cover a wide range of problems in biotechnology, petroleum, petro chemistry, environmental chemistry, specialty chemicals, photochemistry and food. His research ranges from industrial plant operation to elementary reaction mechanisms. 